Instructions for authors, subscriptions and further details:

http://brac.hipatiapress.com

\title{
El Cuerpo como Eje de la Memoria del Teatro: del Rito a las
}

\section{Artes Parateatrales}

Teresa Colomina Molina ${ }^{1}$

1) Departamento de Expresión Plástica, Musical y Dinámica de la Facultad de Educación de la Universidad de Murcia.

Date of publication: February $3^{\text {rd }}, 2022$

Edition period: February 2022 - June 2022

To cite this article: Colomina, T. (2022). El Cuerpo como Eje de la Memoria del Teatro: del Rito a las Artes Parateatrales. Barcelona, Research, Art, Creation, 10(1), 64-82. doi: 10.17583/brac.6689

To link this article: https://doi.org/10.17583/brac.6689

\section{PLEASE SCROLL DOWN FOR ARTICLE}

The terms and conditions of use are related to the Open Journal System and to Creative Commons Attribution License (CC-BY). 
BRAC - Barcelona Research Art Creation. Vol. 10 No. 1, February 2022, pp. 64-82

\section{The Body as Axis of Theater Memory: from the Rite to the Paratheatrical Arts}

Teresa Colomina Molina

Departamento de Expresión Plástica, Musical y Dinámica de la Facultad de Educación de la Universidad de Murcia.

(Received: 20 September 2020; Accepted: 25 June 2021; Published: 3 February 2022)

\section{Abstract}

Theatre seems to have a direct correspondence with the dramatic text, however, acting work are articulated using the body. The meanings of ritual, theatre and the paratheatrical are investigated, carrying out a bibliographical review and a descriptive analysis of the most significant terms and theories that explain the relationship of these three concepts. First part, entitled Origin, explores the genealogy of theatre in order to understand the similarities between rituality and theatricality. The second part, the body, analyses the two main dramatic currents of the 20th century: the physical and the psychological theatre. The main differences are confronted to establishing the origins and interpretative modes that define both. The last part, the paratheatrical, focuses on classifying those activities considered non-theatrical, but which make use of body interpretation such as performance, flashmob or drama therapy, into three categories: artistic, political-social and healing. In conclusion, it can be established that theorists such as Eli Rozik disagree on the evolution from ritual to theatre, opening up a perspective of rethinking ritual and theatre as parallel activities, and that the resurgence of the corporal represents a turning point in the contemporary scene, making possible to open up to new paradigms and forms of interpretation that contribute to the improvement of self-knowledge and inter-human communication.

Keywords: Rite, theatricality, paratheatrical, corporal, physical theatre 
BRAC - Barcelona Research Art Creation. Vol. 10 No.1, February 2022, pp. 64-82

\section{El Cuerpo como Eje de la Memoria del Teatro: del Rito a las Artes Parateatrales}

Teresa Colomina Molina

Departamento de Expresión Plástica, Musical y Dinámica de la Facultad de Educación de la Universidad de Murcia.

(Recibido: 20 setiembre 2020; Aceptado: 25 junio 2021; Publicado: 3 febrero 2022)

\section{Resumen}

El teatro parece tener una correspondencia directa con el texto dramático, sin embargo, el trabajo actoral se articula mediante el uso del cuerpo. Se investigan las significaciones del ritual, el teatro y lo parateatral, realizando una revisión bibliográfica y un análisis descriptivo de los términos y teorías más significativas que esclarecen la relación de estos tres conceptos. La primera parte titulada origen indaga en la genealogía del teatro para comprender las similitudes entre ritualidad y teatralidad. La segunda parte, el cuerpo, analiza las dos corrientes dramáticas principales del siglo XX: los teatros físico y psicológico. Se confrontan las diferencias principales para establecer los orígenes y estilos interpretativos que definen a ambos. La última parte, lo parateatral, se centra en clasificar aquellas actividades consideradas no teatrales, pero que hacen uso de la interpretación corporal como el performance, el flashmob o la dramaterapia, en tres categorías: artística, político-social y sanadora. A modo de conclusión se puede establecer que teóricos como Eli Rozik discrepantes sobre la evolución del ritual al teatro, sugieren una posibilidad de repensar rito y teatro como actividades paralelas. Y que el resurgir de lo corporal marca un punto de inflexión en la escena contemporánea, posibilitando la apertura a nuevos paradigmas y formas interpretativas que contribuyen a la mejora del autoconocimiento y la comunicación interhumana.

Palabras clave: Rito, teatralidad, parateatral, corporal, teatro físico 
En qué pensamos cuando decimos la palabra teatro? La mayoría de los interpelados responden que la primera imagen que les trae el recuerdo es la de un grupo de actores y actrices sobre el escenario recitando su texto. Ya tenemos las primeras palabras clave: escenario y texto. Y si siguiéramos indagando la apariencia de ese escenario sería probablemente la de un teatro convencional a la italiana. Escena y patio de butacas enfrentados, delimitados por el proscenio, esa línea divisoria que marca el final de las tablas. El texto bien podría ser de algún dramaturgo clásico o quizás, de una autora contemporánea. Sin embargo, pocos se acuerdan de la existencia de los teatros físico y gestual, u otras disciplinas consideradas parateatrales como el rito, la danza o el performance que utilizan la interpretación o la expresividad corporal como recurso comunicativo. De estas reflexiones surgen los siguientes interrogantes: ¿Por qué el teatro textual parece tener mayor relevancia sobre lo corporal? ¿Dónde se halla el origen de la teatralidad? ¿Cómo se articulan ritual y teatro en la experiencia parateatral? ¿Por qué lo parateatral no es considerado propiamente teatro?

En este artículo mediante una revisión bibliográfica y un análisis descriptivo de términos, conceptos, teorías y aportaciones científicas se pretende dar respuesta a estos interrogantes desde una dimensión ontológica, así como analizar los resultados obtenidos.

Esta investigación se ha estructurado en tres partes. La primera: el origen, explora la genealogía del teatro desde su raíz antropológica. La segunda: el cuerpo, procura delimitar las diferencias entre los llamados teatro psicológico y teatro físico. En la tercera parte se abordan algunos de los conceptos más representativos de las artes parateatrales y su relación con el teatro.

\section{Origen}

Para Buezo (2004) "Los orígenes del teatro están ligados al culto religioso la sacralización del cuerpo y el espacio. En las ceremonias primitivas encontramos una incipiente teatralidad (hombres disfrazados de animales en las pinturas rupestres)" (p. 28). Seres humanos caracterizados con pieles de animales constituyen lo que se podría denominar el cuerpo encarnado. Adoptando la identidad de otro ser vivo, ente o elemento con el propósito de dominar la naturaleza se emprende una iniciación en lo desconocido, 
combinando magia, ritual y corporeidad, creando códigos de conducta que confeccionan el nacimiento del teatro, a partir de prácticas preteatrales.

Estas ceremonias que se describen carecen de objetividad, de evidencia empírica. Son actos espontáneos que parten de la intuición y arrastran al colectivo a imitar el comportamiento de otros o a personificar la naturaleza. Fenómeno que va forjando una serie de historias y leyendas que con el tiempo el teatro convertirá en mitos.

Es plausible suponer que la motivación principal de tales comportamientos fuese la creencia del ritual como vehículo para interferir en el medio, a través de la mente, desarrollando la energía vital del individuo, y no por el empleo material de la acción física.

En este tipo de celebraciones ritualistas todos los participantes se implican por igual. No existe el espectador. "Los sistemas de comunicación eran intraficcionales, es decir, o todos bailaban, o todos se sumergían en el mismo espíritu participativo" (Oliva y Torres, 2000, p. 13).

Para entender cómo se llega a la ruptura entre ejecutantes y observadores es necesario señalar la figura del devoto. Aquel que junto a otros fieles narra a los convocados las hazañas de su dios, conformando el coro que necesitado de audiencia provocaría la convención teatral. De ahí el término Theátron, que "significa el lugar desde donde se ve o contempla algo" (Vélez, 2015, p. 35). Otra posibilidad para entender la escisión entre rito y teatro pasa por comprender que existe un momento por el cual el ritual presenta una dicotomía que da origen al teatro. Dumoulié (1996) manifiesta que "los ritos se dirigen a los dioses y al Padre, mientras que el teatro se dirige a los hombres" (p. 84). Esta fragmentación entre lo divino y lo terrenal no impide a ambos compartir cierta teatralidad por el uso de elementos escenográficos similares. Sin embargo, la característica que los diferencia principalmente es "que en el rito no se representa, sino que se vive" (de Vicente, 2017, p. 28). En la actualidad se puede observar este efecto en religiones monoteístas, como el catolicismo, donde el rito eclesiástico se impregna de la estructura teatral, pero reafirmando la veracidad de los hechos tratados. La presencia del cuerpo de Cristo y el Espíritu Santo durante la eucaristía son realidad y no fábula. Por tanto, la frontera que difiere entre ceremonia y teatro, sería la representación o no de una ficción.

El teatro griego es descendiente del rito. En el subyacen dos elementos principales: Lo Apolíneo y Dionisiaco. Para (Nietzsche, 1995) Apolo es el dios que encarna la belleza, el equilibrio, y por extensión aquellas disciplinas artísticas que poseen forma armónica e imitativa como pintura, escultura o arquitectura. Dionisio, por el contrario, representa lo mundano e irracional. 
Protector de artes abstractas, liberadoras de la mente como la danza que tiene un arraigo en lo corporal; o la música, provocadora de la exaltación del colectivo, despojan al ser humano de su individualidad utilizando el trance como vehículo para formar parte del todo absoluto. La fusión de estas divinidades opuestas, pero complementarias, inicia el nacimiento de la tragedia ática. Podemos aseverar entonces, que las primeras dramatizaciones parten de la improvisación motivada por el ritual dionisiaco y la imitación de lo apolíneo. Con posterioridad se crearían composiciones dramáticas ceñidas a un texto relator de una historia análoga a la realidad. El concepto de mimesis introducido por Aristóteles en su Poética dice: "La epopeya y la poesía trágica, y también la comedia y la ditirámbica, y en su mayor parte la aulética y la citarística, todas vienen a ser, en conjunto, imitaciones" (Artistóteles, 1974, p. 14-16). Si las tragedias se imitan de acciones de la vida real, es necesario entender el carácter del pueblo griego expuesto en continuas batallas a la muerte; por su idiosincrasia reflexivo y pesimista, sabedor de la imposibilidad de permanencia opta por el dominio de las ideas. Forzando que lo intelectual prevalezca sobre lo sensitivo. Generando una ruptura con la naturaleza y lo dionisiaco se establecen normas y códigos que deshumanizan, perdiendo la intuición y negando el instinto. "Este drástico cambio impuso una nueva estructura en las tragedias, pues se construyeron para el entendimiento, para acceder a ellas por medio de la razón" (Espíndola, 2016, p. 55).

$\mathrm{Si}$ al principio, la memoria colectiva y la trasmisión oral resuelven la no perdurabilidad del teatro, finalmente se impone la figura del dramaturgo que compila estas historias mantenidas en el tiempo por relación intergeneracional. Según Jelin (2002) "El núcleo de cualquier identidad individual o grupal está ligado a un sentido de permanencia" (p. 24). El texto escrito es tangible, brinda la oportunidad de salvaguardar la cultura y los acontecimientos que la memoria podría perturbar. Al contrario del cuerpo que es mortal, la palabra escrita permanece. La acción teatral es un acto efímero, en clara desventaja con las artes plásticas que son más longevas. De hecho, parte de lo que sabemos del teatro griego se ha estudiado a través de la evidencia arqueológica de las pinturas impresas en vasijas para uso cotidiano o ritual (Reznik, 2019).

\section{Cuerpo}

El cuerpo humano es generador de placeres y sufrimiento, un espacio vulnerable esclavo de las pasiones y los instintos primarios estrechamente relacionado con Dionisos. Aunque como apunta Ibañez (2013) el 
autoconocimiento y la exploración del propio cuerpo podrían ser sinónimo de querer experimentar la vida y profundizar en lo físico más allá de la razón, por el contrario, en el campo humanístico para (Planella, 2006) el cuerpo ha sido un elemento considerado inferior a mente y alma. Partiendo desde esta perspectiva, es comprensible que, a lo largo del tiempo, lo corporal se asocie a un estamento más vulgar, menos intelectual. Un ejemplo en la antigüedad clásica es la pantomima romana que se nutre de la actividad corporal y física del actor. Tiene por objeto divertir al pueblo, al igual que el circo romano o las luchas de gladiadores, que eran puro entretenimiento (Perea, 2004). A su vez, este estilo influye sobre los actores de la Edad Media. Cabe recordar que la caída del Imperio Romano construye un nuevo mapa político a causa de las invasiones bárbaras. Grupos de titiriteros itinerantes pululaban por los mercados y las plazas, trayendo consigo nuevas memorias, arraigadas en su cultura (Corvo, 2006). Para hacerse entender dentro de la variedad de lenguas y dialectos, el gesto debía prevalecer sobre la palabra. Los temas tratados en estas comedias, farsas y espectáculos no fueron siempre bien acogidos por la Iglesia. El contenido blasfemo e hilarante sobre temas religiosos junto a la exhibición sin pudor de los cuerpos contoneándose en la escena, condujo este subgénero a la censura. En las artes plásticas se hallan ejemplos de la representación de cuerpos desnudos, que, si bien podemos observar en la antigüedad clásica la musculatura cincelada de los Kurois griegos o en infinidad de figuras alegóricas del Renacimiento, estas no dejan de significar un patrón de cómo o quién puede mostrar la desnudez de lo físico (Mendiola, 2010).

El carnaval es una actividad parateatral de origen pagano, proveniente de la Saturnalia romana. Frazer (2006) describe como "los amos cambiaban su puesto con los esclavos y les servían” (p. 658). Durante el Carnaval todos se involucran en la acción, nadie contempla. Las identidades se alteran, los unos pasan a convertirse en otros. Sobreviene la memoria colectiva relacionada con el rito de Dionisos. Ocasionando un intercambio de roles muy similar al hecho dramático y al "role play" (Jacques et al., 2018, p. 32). El Santo Oficio censura todas aquellas manifestaciones que exhiben el cuerpo de forma provocativa (Gacto, 2000), la festividad del Carnaval logra mantenerse al orientar su propósito al ayuno cuaresmal. Su origen etimológico viene de las palabras latinas carnis y levamen que se traduce por dejar la carne, tanto en el plano alimenticio como carnal (Lozica, 2007). Ya que, si para el cristianismo el cuerpo es el vehículo que une lo divino con lo humano, puesto que Dios se hizo carne mediante la personificación de Jesús (Gesché, 2014), había que preservar lo corporal de lo impúdico. 
Este prolegómeno ha servido para comprender la visión de lo corporal en los inicios del arte teatral, y cómo el cuerpo ha sido vetado por un sistema de creencias sociales, filosóficas, políticas y religiosas.

El influjo de las vanguardias artísticas del siglo XX gesta la aparición del denominado teatro físico. Desplazando la razón en favor del universo del inconsciente y las emociones. Uno de los autores que reclama una preponderancia de lo físico sobre lo racional es Antonin Artaud (1996) que en sus manuscritos expresa: "El dominio del teatro hay que decirlo no es psicológico, sino plástico y físico” (p. 82). En su obra aboga por una renovación del teatro regresando a su origen ritual, ya que, en lo dionisiaco, el ser humano alcanza la verdadera libertad y conecta con su legítima naturaleza: lo instintivo e irracional. Convencido de la capacidad regeneradora que tiene el teatro sobre el espíritu. Para ilustrar estos razonamientos recurre a cuatro metáforas: al igual que la alquimia se le presuponía la capacidad de transformar en oro los metales, el rito se trasmutó en teatro. Incluye el teatro balines como paradigma de espectáculo codificado y sublime que otorga mayor relevancia al gesto con respecto a la palabra. Utiliza una pintura sobre las hijas de Lot para reclamar la importancia de la percepción sensorial en el contexto escénico. Y, por último, compara al teatro con la peste como elemento transformador. En definitiva, sin negar el uso de la palabra propone un teatro en el cual la expresión corporal y el gesto ganen autonomía frente al texto.

Para (Sánchez Montes, 2004) existen otros autores anteriores a Artaud que revindican la eficacia orgánica, sin artificio de la fisicidad actoral, como Adolphe Appia, Edward Gordon Craig, Vsevolod Meyerhold y Constantin Stanislavski. Para Appia la importancia de la interpretación radica en el cuerpo físico actoral que mediante el movimiento es capaz de expresar más allá de la palabra, al contrario que Craig que supedita el cuerpo al movimiento, y ansía que el cuerpo del actor sea despojado de su humanidad y actúe como una máquina (Sánchez Montes, 2004; Martínez Agíss, 2016).

Stanislavski influenciado por el naturalismo, en su primera etapa como director teatral asienta como base de su labor escénica, la memoria emotiva, y la entiende como la capacidad de sentir y no de imitar los sentimientos. Procurando al personaje unas emociones traídas del recuerdo personal del actor. En la segunda etapa opta por fusionar la interpretación psicológica y corporal. Introduce el método de las acciones físicas. Donde el cuerpo cobra importancia por dotar al actor de expresión comunicativa con simultaneidad a la palabra. Completando su pedagogía con lo que se conoce por Sistema Stanislavski. Concepto que en su opinión es inexacto, ya que él no inventa 
nada, pues el binomio cuerpo-espíritu es común al ser humano (Stanislavski, 1980). Tal y como apunta (Salgado, 2007) resulta más sencillo entender el término espíritu si lo cambiamos por psíquico, al englobar mente, voluntad y sentimientos. De la misma forma Meyerhold (1998) discípulo de Stanislavski aprecia que la importancia interpretativa del actor radica en que el público pueda entender mediante el gesto físico la emoción del personaje, y no tanto si intérprete y personaje comparten emociones.

En varias conferencias impartidas por (Grotowski, 1993; 2008) se argumenta como a partir del método de Stanislavski, él mismo crea su concepto cuerpo-memoria, donde la memoria no es un ente independiente del cuerpo, es que el cuerpo actúa inducido por la memoria, en sentido opuesto a Stanislavski porque se puede dominar el cuerpo, pero no los sentimientos ya que estos no pertenecen a la voluntad. Se puede fingir un sentimiento, pero la aparición verdadera es un acto espontáneo, instintivo que escapa de la razón.

Tras la muerte de Stanislavski algunos de sus discípulos como Vladímir Nemiróvich-Dánchenko, María Knébel, Evgueni Vajtángov o Lee Strasberg continúan únicamente con los métodos psicológicos y realistas de interpretación (Saura, 2015). Lo que da lugar a una clara diferenciación entre teatro físico y teatro psicológico.

\section{Tabla 1}

\begin{tabular}{l|l}
\hline \multicolumn{1}{c|}{ TEATRO FÍSICO } & \multicolumn{1}{c}{ TEATRO PSICOLÓGICO } \\
\hline $\begin{array}{l}\text { Origen en el ritual } \\
\text { prearistotélico }\end{array}$ & Origen en el teatro griego \\
\hline Parte de la improvisación & Parte del texto dramático \\
\hline $\begin{array}{l}\text { Se genera mediante la } \\
\text { improvisación }\end{array}$ & La improvisación es solo un medio \\
\hline Creación a través del cuerpo & Creación a través de las emociones \\
\hline Expresa por con el cuerpo & Expresa mediante los sentimientos \\
\hline Puede ser actor o bailarín & Ha de ser actor \\
\hline Influenciado por otras culturas & Propiamente occidental \\
\hline $\begin{array}{l}\text { El personaje se construye } \\
\text { desde el presente del actor }\end{array}$ & $\begin{array}{l}\text { La construcción del personaje parte de recuerdos } \\
\text { y vivencias propias del pasado del actor }\end{array}$ \\
\hline Actor creador & Actor interprete \\
\hline Interpreta la vida & Vive la interpretación \\
\hline Imita la vida y la materia & Imita al ser humano \\
\hline
\end{tabular}


La Tabla 1 está basada en un estudio de (Colomina, 2019) que se ha decidido ampliar en base a los datos que se aportan en esta investigación. Como ya se ha visto el origen del teatro físico se remonta a ritos primitivos, mientras que el teatro psicológico perteneciente al realismo y el naturalismo guarda relación con la tragedia griega, puesto que la psicología propia de cada mito es fundamental para lograr en el público la identificación con el personaje bajo el efecto de "catarsis" (Aristóteles trad. 1974). Entendiendo esta como un proceso de redimirse de las pasiones que en cierto modo, compartiría una función terapéutica con la bacanal dionisiaca.

El teatro físico crea desde la improvisación y expresa a través del cuerpo, pudiendo mezclar disciplinas de danza y teatro, con manifestaciones artísticas provenientes de otras culturas: Butoh, Kathakali, Danza balinesa... (BrozasPolo y Vicente-Pedraz, 2017). El actor físico crea desde su inmediatez, no busca compartir sentimientos con su personaje. De hecho, para Lecoq "Los actores interpretan mal los textos que les conciernen demasiado" (2004, p. 38). En cambio, en el teatro psicológico la creación y la expresión se centran en la emoción que siente el personaje, que es interpretado por un actor de texto, ayudado de recuerdos propios. Para Alsina en el teatro de Stanislavski la improvisación "tiene el objetivo de la construcción de un contexto, de una situación con determinados elementos, entre los cuales, existe uno, el texto, que precede, como objeto literario escrito por un dramaturgo, a los ensayos" (2017, p. 152). La improvisación en el teatro naturalista es solo un mecanismo que posibilita al intérprete adentrarse en el texto teatral.

$\mathrm{El}$ actor y la actriz físicos sienten interés por crear su propio espectáculo. No necesitan del autor o de la directora de escena. Jacques Lecoq sostiene la idea de formar personalidades creadoras donde "la interpretación es la prolongación de un acto creador” (Lecoq, 2004, p. 35). Fundó en París, la escuela internacional que lleva su nombre, concibiendo una metodología de movimiento corporal basada en la imitación de la vida y la materia, porque todo en el universo contiene un "fondo poético común" (Lecoq, 2004, p. 71). Ya que todo ser vivo y elemento puede ser imitado y expresado por el cuerpo. Brinda a su alumnado un modelo de observancia de la naturaleza que le faculta para diseñar a partir de lo que es capaz de constatar. No es lo mismo el agua contenida en un vaso que la de la corriente de un río porque las formas de manifestarse una y otra presentan unas diferencias de carácter dramático, útiles para marcar el desarrollo en la configuración del movimiento del personaje. La expresión de un personaje estático contra la de otro con una fisicidad arrolladora. 


\section{Parateatral}

En este apartado se van a mostrar otras formas teatrales no incluidas como categorías dramáticas en el teatro tradicional o en el teatro de vanguardia, pero que se construyen bajo el influjo del panorama teatral más trasgresor del último siglo.

El diccionario de términos teatrales de Patrice Pavis (1998) define parateatral como la "actividad dramática, teatral en sentido amplio, que recurre a procedimientos tomados del teatro, pero que no aspira a una realización estética y se sitúa al margen de la institución” (p. 326).

En Europa, uno de los pioneros en llevar a la práctica actividades parateatrales, influido por la teoría artaudiana fue Grotowski. Básicamente trata de ahondar en el misticismo y en las relaciones interhumanas, propiciando que el público abandone la pasividad del patio de butacas (Pessolano, 2014). Algunas compañías teatrales desde una perspectiva meramente estética desean conocer qué elementos ofrecidos por otras culturas son válidos por su exotismo para enriquecer sus creaciones. Otros, guiados por la búsqueda de lo sagrado, se adentran en descifrar códigos interpretativos que retrotraigan a un estadio anterior a la ficción porque ahondar en la preexpresividad supone despojar al cuerpo del actor del movimiento heredado por su cultura, capacitándolo en el manejo de una mejor organicidad expresiva (Barba, 1994).

Mismamente, Eugenio Barba (1997) miembro fundador del teatro antropológico expone el concepto de tercer teatro. Un teatro aprendido de manera autodidacta, alejado de los centros culturales neurálgicos, realizado por ciudadanos anónimos, que quizás su propósito sea compartir la condición humana entre semejantes. Un evento socializador donde "las intenciones, las aspiraciones, las necesidades personales empiecen a transformarse en hechos" (p. 2). En Brasil, (Boal, 1980) concienciado por los problemas de los más desfavorecidos funda el teatro de los oprimidos. Trabajando desde una óptica de lo social, elabora estrategias para reconvertir al espectador en parte activa de la función. Su proceso de adaptación comienza por la toma de conciencia de las limitaciones y deformaciones que el cuerpo de los campesinos ha sufrido por el oficio que desempeñan. Ya que hay mayor costumbre de expresar con la palabra, se debe ampliar el horizonte de lo físico. El espectador pasa a convertirse en autor realizando una dramaturgia simultánea con los actores. Pueden escoger textos no dramáticos, como noticias publicadas en prensa para crear una historia. El público también interviene en la interpretación, realizando pequeñas improvisaciones sobre alguna temática 
social que ataña a la comunidad, en lo que se conoce como teatro foro; o practicando el teatro invisible, realizado en espacios públicos, como una tienda o un restaurante, donde los presentes no averiguan hasta el final que los hechos a los que involuntariamente asisten conforman una ficción.

A finales del siglo XIX, existió un icono feminista llamado Jane Harrison que formó parte del grupo de los ritualistas de Cambridge (Bauzá, 2003), un selecto club de antropología victoriana que sostenían que aquello que representaba mejor a la antigua Grecia, era el rito y no la tragedia. Harrison pondera que "si estuviésemos totalmente satisfechos no tendríamos representación, ni memoria, ni mímesis, ni drama, ni religión" (Jane Harrison citada en Racionero, 2014, p. 2). El anhelo de cambiar nuestra existencia, de mejorar eventos pasados o futuribles hace que el ser humano busque una cierta ritualidad compositiva para reafirmarse y progresar. Paralelamente en algunos contextos sanitarios, las artes son introducidas como tratamiento psicológico por profesionales de la salud bajo el epígrafe de Arteterapia. Guiote (2013) aclara el término alegando ser "un medio para acceder al mundo interior mediante la expresión creativa, y entre sus funciones, las posibilidades como desencadenante para facilitar: el reconocerse mediante las obras artísticas; el identificarse entendiendo la obra como espejo, como huella, o marca" ( $p$. 173). Aquí la experiencia artística ejerce de canal entre el paciente y su inconsciente, permitiendo el autoconocimiento del sujeto. Una subcategoría de la Arteterapia, es la teatroterapia o dramaterapia. Para (Klein, 2017) la dramaterapia se abastece de técnicas propias del teatro para alcanzar la sanación. Para ello, el teatro funciona como un catalizador. Las acciones, la expresión corporal y el juego dramático ayudan a expresar recuerdos dolorosos de una forma más liviana.

Tenemos la capacidad de introspección sobre la historia de cada uno, en rememorar el pasado, y desarrollar un propio autoconocimiento. Mientras esto ocurre se permanece en un estado transitorio. Para (García-Manso, 2018) El teatro se caracteriza por ser liminal: se traspasa la frontera del yo pasado, al yo futuro por medio del juego simbólico. La dimensión plástica del teatro que señalaba Artaud refleja la capacidad de ruptura en la linealidad temporal del acto escénico.

El concepto posdrama muestra una alteración en el orden cronológico de la partitura teatral. El discurso se fragmenta y el público ha de recomponer aquello que observa en la escena. Esta desfragmentación abarca el territorio de la imagen y es propia del tiempo presente, por lo que el espectador está familiarizado con este recurso utilizado con equivalencia en otros contextos: noticiarios, programas de televisión, cine y publicidad. La variedad de planos 
permite establecer una multiciplidad de enfoques y discursos, generando elipsis narrativas. Aunque su origen, de apariencia más elemental se remonta a "la escena simultanea del teatro en la Edad Media" (Hartwig, 2004, p. 44).

Con la globalización todo se fragmenta, desde los hábitos de consumo y producción hasta las formas de crear arte. En internet aparece una nueva modalidad artística y de interacción social llamada "artivismo" que se define como la unión de las palabras arte y activismo (Aladro-Vico et al., 2018, p. 10). De estas experiencias surgen pequeñas improvisaciones corporales de tipo coreográfico, a veces improvisadas, otras pactadas, grabadas y compartidas en diferentes redes sociales. Son los llamados "Flashmobs" (Marcillas, 2013). Para la autora, estas acciones producen un proceso aproximado a la catarsis aristotélica del público reconvertido en actuante durante el momento en que se desarrolla el flashmob. El universo de lo virtual proporciona asistir a eventos en cualquier punto del planeta sin la corporalidad del espectador.

En el performance se comienza a percibir una necesidad por lo real. Un cambio de paradigma entre lo representativo y lo performativo en el acto de comunicar. "La expresión es, por definición, corpórea. No es posible la expresión fuera o al margen del cuerpo. Del cuerpo entendido como corporalidad (integración armónica de múltiples cuerpos: físico, mental, emocional, energético, espiritual...) y no mero organismo" (Toro-Alé 2004, p. 155). Performance es el arte de acción que proyecta el cuerpo mediante contenidos sígnicos y en ocasiones involucra al espectador (Tejo, 2019).

Da costa Dias (2020) apunta al título de la obra de Calderón de la Barca El gran teatro del mundo como metáfora de la vida real convertida en escena. El instante en que el actor se niega encarnar un personaje porque prefiere sentirse él mismo protagonista, nos sitúa ante un hecho performativo. A través del cuerpo, el performer se auto-expresa. Compone un relato de él o ella misma involucrando de manera interdisciplinar las bellas artes, el feminismo, la ecología, la sociología y la filosofía.

$\mathrm{Al}$ principio el ámbito de la performance se halla en galerías de arte, se relaciona con la pintura abstracta, recordemos el actión painting de Pollock, donde el proceso prima sobre el resultado. Hasta que el teatro bebe de la performance y viceversa. Para París-Romia (2020) "los diferentes medios artísticos se empiezan a relacionar de muchas maneras diferentes, creando obras híbridas que se extienden más allá del propio lenguaje en las que han sido realizadas" (p. 103). Se generan dicotomías sobre los conceptos de improvisación e interrelación. El teatro se ensaya y la performance responde, al menos, a un guion o idea preconcebida. 
De otra parte, se encuentra el videoperformance, donde el creador busca de manera consciente una imbricación con el lenguaje de las artes visuales. Sin perder su esencia performativa del aquí y el ahora, ya que la falta de contacto directo con el público no interfiere en la performatividad de crear nuevas realidades. Las redes sociales suscitan una nueva interacción comunicativa entre el artista y los espectadores, a base de likes, emoticonos y el intercambio de mensajes de texto. Por lo que toma relevancia el concepto mismo que se quiere transmitir y no el resultado (San Cristóbal, 2018).

\section{Discusión y Conclusiones}

Está aceptado que el teatro tiene sus orígenes en rituales ancestrales de carácter místico. Esta tesis es la más defendida en nuestro tiempo y parte de los argumentos esgrimidos durante el siglo XIX por eruditos de diferentes disciplinas como James Frazer o Jane Ellen Harrison, citados en este artículo. Por otra parte, el acreditado teatrologo Eli Rozik, opina que esta teoría es errónea y describe la suya propia. Es posible que aun siendo ciertas las ideas de Rozik sobre el teatro en general, no se invalide la correspondencia de los rituales dionisiaco y apolíneo con la tragedia griega. Las razones que plantea son que teatro y rito "operan en diferentes niveles ontológicos" (Rozik, 2014, p. 351). El rito se proyecta para establecer una comunicación con lo divino, y el teatro con lo terrenal. Argumenta que en el teatro el público es consciente de hallarse ante una ficción, lo que no ocurre en el rito. La fuerza que impulsa al ser humano a teatralizar es la necesidad de representar las imágenes del inconsciente. Y alternativamente lo hace mediante la expresión artística y el juego imaginativo. Rozik cita a Piaget para explicar que "la imaginación y la posibilidad fundamental de su comunicación son las raíces existenciales del teatro" (2014, p. 359). El juego simbólico que es propio en el estadio infantil plasma el pensamiento mediante la recreación interpretativa, que con la madurez y la entrada en la edad adulta se va perdiendo, en parte por presión social. El teatro es para Rozik una convención social que facilita construir una regresión a y por lo lúdico.

Desde todas las perspectivas, ya sea de forma paralela o evolutiva, teatro y rito se nutren de la acción. La memoria emotiva de la que habla Stanislavski se centra en llegar a la emoción que es irreflexiva, a través del movimiento físico, de forma deliberada bajo la voluntad misma del actor. Acto por consecuencia que no difiere del objetivo dionisiaco de embriagarse de las pasiones que el cuerpo sea capaz de sentir. Por tanto, el cuerpo en movimiento 
es un instrumento canalizador capaz de conectar con la naturaleza de lo emotivo.

La intención nuestra no es demonizar el teatro de texto. El oficio del escritor se configura relatando momentos de la vida interior del individuo o de aquello que le rodea. El arte de escribir lleva aparejada la necesidad de relatar. La escritura opta por liberar el inconsciente, ya que "el acto de escribir genera sus significados de modo autónomo, porque es automático, irreflexivo, como el danzar" (Jiménez Morato, 2018, p. 21). Hay una relación entre el arte de escribir, de ahondar en uno mismo, y la interpretación, como también lo hay en toda disciplina artística porque en sí misma prevalece la motivación creadora. Pero si el teatro es ante todo acción, gesto y cuerpo, la narrativa debiese considerarse como una herramienta similar a la música o los decorados. Enriquecen más no son necesarios. El problema es que en occidente durante siglos se ha abusado del texto dramático hasta parecer una pieza indispensable del entramado teatral.

El teatro comporta introspección y proyección. Al ser un juego, una ficción, permite mostrar nuestra naturaleza interna de soslayo, es decir, tolera la rectificación. Por esto es tan importante en la Arteterapia. En la actualidad la dramaterapia resulta ser un canal sanativo equiparable al que realizaba el curandero con la tribu. La interacción entre arte y medicina no es nueva. Existen vestigios de civilizaciones antiguas que organizaban actividades creativas como una labor terapéutica en torno a las artes visuales y la música (López, 2010). La figura del chaman comenzó su andadura en sociedades primitivas como intentos de comunicación con el objetivo de ganar la indulgencia, agradecer o vencer a aquellos fenómenos inexplicables que ponen al ser humano en una tesitura de vulnerabilidad. En el presente las personas que siguen una formación como arteterapeutas ejercen de maestros de ceremonia utilizando lo teatral como procedimiento de sanación. En general somos seres frágiles, pero con un alto grado de resiliencia porque somos capaces de reinventarnos. Es decir, de cambiar, de transmutar, de reconvertirnos en un otro mejorado.

Las artes consideradas parateatrales son influenciadas por la teatralidad que comparten el rito y el teatro, y a su vez, las podríamos clasificar en tres grandes grupos: curativas, sociopolíticas y artísticas. La teatroterapia o dramaterapia pertenecen a la primera categoría, formando un segmento aislado. El tercer teatro, el teatro social de Augusto Boal, y el flashmob se articulan en un contexto ideológico. Las exploraciones ceremoniales de Grotowski y el teatro antropológico de Eugenio Barba tienen un sentido de investigación artística, al igual que el performance. Sin embargo, los 
performances, además, pueden mostrar una necesidad reivindicativa con un sentido estético. Arte e ideales se hibridan entre sí, como las propuestas realizadas por la artista Orlan de alteración e intervención sobre su propio cuerpo (Silva, 2016).

El teatro tiene una faceta de divulgación cultural, pero también de sentimientos, por tanto, es liberador, tanto para el actuante como para el que observa. Los impulsores de la interpretación física han conseguido en el siglo XX devolver al teatro su esencia corporal, y con igual importancia aprender a crear desde la subjetividad y construir autoreferencias. Un ejemplo de esto es el teatro autobiográfico de la española Angélica Liddell o de la actriz argentina Camila Sosa Villada.

Considerar teatro únicamente al arte que emerge en la antigua Grecia, condiciona la percepción sobre este, y se le atribuye, por defecto una elaboración exclusivamente occidental. Todo lo que no esté relacionado, aunque sea indirectamente con el teatro europeo, no se le ha considerado arte escénico. Esta concepción sesgada genera, por tanto, un etnocentrismo que niega aquellos modelos teatrales que no se ajustan a esta premisa, y los clasifica como hechos parateatrales (Rodríguez, 1990). Por este motivo apremiamos a continuar en futuras investigaciones ahondado en los conceptos genuinos de ritual, teatro primitivo y parateatralidad de otras culturas en la búsqueda de su propia referencialidad. "El hombre no tiene naturaleza, sino que tiene... historia" (Ortega y Gasset citado en Alonso, 2020, p. 83). El autor con esta frase da a entender que el ser humano, más que formar parte de la naturaleza, tiene la capacidad de distanciarse y adaptarla a sus necesidades. Nacemos siendo nada y nos construimos a lo largo de nuestra historia con la memoria y el recuerdo. La necesidad de ficcionar acciones a través de la expresión corporal y mostrarlas a otros es inherente al ser humano y no producto del mestizaje. Retornar al gesto, a la memoria de lo físico, posibilita el conocimiento de los límites del sujeto porque el cuerpo es la frontera entre nuestro pensamiento y el entorno que se habita.

\section{Referencias}

Aladro-Vico, E., Jivkova-Semova, D. y Bailey, O. (2018). Artivism: A new educative language for transformative social action. [Artivismo: Un nuevo lenguaje educativo para la acción social transformadora]. Comunicar, 57: 09-18. https://doi.org/10.3916/C572018-01 
Alonso, M. (2020). El hombre no tiene naturaleza: Un examen de la metafísica orteguiana. Revista de Filosofía, 45(1), 69-85. https://doi.org/10.5209/resf.68167

Alsina, C. M. (2017). De Stanislavski a Bretch: Las acciones físicas. Teoría y práctica de procedimientos actorales de construcción teatral. Editorial Argus-a.

Aristóteles. (1974). La poética de Aristóteles. Editorial Gredos.

Artaud, A. (1996). El teatro y su doble. Pocket Edhasa.

Barba, E. (1994). La canoa de papel. Tratado de antropología teatral. Catálogos editora.

Barba, E. (1997). Teatro. Soledad, oficio y revuelta. Catálogos.

Bauzá, H. F. (2003). Leituras do mito e a Escola de Cambridge. Anos 90, 10 (17): $35-44$.

Boal, A. (1980). Teatro oprimido. Nueva Imagen.

Brozas-Polo, M. P. y Vicente-Pedraz, M. (2017). La diversidad corporal en la danza contemporánea: una mirada retrospectiva al siglo XX. Arte, $\begin{array}{lllll}\text { Individuo } \quad y \quad \text { Sociedad, } & 29 & \text { (1): } & \text { 71-87. }\end{array}$ https://doi.org/10.5209/ARIS.51727

Buezo, C. (2004). Prácticas festivas en el teatro breve del siglo XVII. Teatro del siglo de oro. Estudios de Literatura, vol. 84. Edition Reichenberger.

Colomina, T. (2019). La pintura abstracta como herramienta en la identificación de las emociones del personaje clásico. Anagnórisis: Revista de investigación teatral, (20), 82-100.

Corvo, M. J. (2006). Historia y tradición en la enseñanza y aprendizaje de lenguas extranjeras en Europa (III): Roma. Babel-AFIAL: Aspectos de Filoloxía Inglesa e Alemá, 15, 43-64.

Da Costa Dias, L. (2020). Crisis de representación, giro performativo y presencia: posibilidades hacia una filosofía-performance. Revista Brasileña de Estudios de Presencia, 10 (1): 1-20. https://dx.doi.org/10.1590/2237-266092575

de Vicente, C. (2017). Teatro crítico latinoamericano: Elementos teóricos para desarrollar un campo de investigación. Revista de la Academia, 24: 25-70. https://doi.org/10.25074/0196318.0.53

Dumoulié, C. (1996). Nietzsche Y Artaud por una ética de la crueldad. Siglo Veintiuno editores.

Espíndola, L. A. (2016). Musicalidad, razón y violencia en la tragedia nietzscheana: del oído a la preeminencia de la vista en la educación. Murmullos Filosóficos, 5(11), 43-56. 
Frazer, J. (2006). La rama dorada. Magia y religión. Fondo de Cultura Económica.

Gacto, E. (2000). El arte vigilado (sobre la censura estética de la Inquisición española en el siglo XVIII). Revista de la Inquisición:(intolerancia y derechos humanos), (9), 7-68.

García-Manso, L. (2018). Espacios liminales, fantasmas de la memoria e identidad en el teatro histórico contemporáneo. Signa: Revista de la Asociación Española de Semiótica, 27, 393-417. https://doi.org/10.5944/signa.vol27.2018.18988

Gesché, A. (2014). La invención cristiana del cuerpo. Franciscanum. Revista de las ciencias del espíritu, 56(162), 166-202.

Grotowski, J. [Cátedra Permanente Jerzy Grotowski] (13 de abril de1993). Los ejercicios [Video]. YouTube. https://www.youtube.com/watch?v=uYaC5HhdG9w

Grotowski, J. (2008). Reply to Stanislavsky. Trad. Salata, K. TDR (1988), 52(2), 31-39.

Guiote, A. (2013). Arteterapia como acompañamiento para la construcción y empoderamiento de la subjetividad femenina. Investigaciones Feministas, 4:

171-199.

https://doi.org/10.5209/rev_INFE.2013.v4.43888

Hartwig, S. (2004). Descentralización visual: la escena fragmentada del teatro español contemporáneo. Bulletin of Hispanic Studies, 81(1): 43-53. https://doi.org/10.3828/bhs.81.1.4

Ibáñez, M. (2013). El cuerpo como centro de interpretaciones. En Muñoz, M y Vela, L. (eds.), Afecciones, cuerpos y escrituras, 87-101. Colección Cuadernos de Cuyo. IFAA.

Jacques, R., Régnier, J-C. y Acioly-Régnier, N. (2018). Educar a través de la investigación, educar a través del juego: El role-playing game (RPG) como estrategia de enseñanza en la educación superior. Revista Akadèmeia, 17, 2, 24-42.

Jelin, E. (2002). Los trabajos de la memoria. $2^{\circ}$ edición. Siglo XXI editores. Jiménez Morato, A. (2018). Un dios que sepa bailar: la performance privada, el gesto más radical. Cuadernos de Música, Artes Visuales y Artes Escénicas 13 (2): 15-25. http://doi.org/10.11144/javeriana.mavae132.udqs

Klein, J. P. (2017). Teatro y dramaterapia (Vol. 50). Ediciones Octaedro. Lecoq, J. (2004). El cuerpo poético. Una pedagogía de la creación teatral. Alba Editorial. 
López, M. D. (2010). Arteterarpia. Concepto y evolución histórica. Diego Marín editores.

Lozica, I. (2007). Carnival: A Short History of Carnival Customs and Their Social Function. Narodna umjetnost, 44(1): 71-92.

Marcillas Piquer, I. (2013). Flashmobs: la transformación de la dramaturgia a través de las redes sociales. Teatro e Internet en la primera década del siglo XXI, en José Romera Castillo (ed.), Editorial Verbum: 235249.

Martínez Agíss, O. (2016). Ser o no ser: la identidad, desde el autómata al androide, en la escena. Telondefondo. Revista De Teoría Y Crítica Teatral, 11(23), 143-154. https://doi.org/10.34096/tdf.n23.2494

Mendiola, I. (2010). Desnudo y desnudez: lecturas biopolíticas del cuerpo exhibido y expuesto. M. Aguiluz, y P. Lazo, Corporalidades, 133-158.

Meyerhold, V. (1998). Teoría teatral. Editorial Fundamentos.

Nietzsche, F. (1995). El nacimiento de la tragedia. Alianza Editorial.

Oliva, C. y Torres, F. (2000). Historia básica del arte escénico. Catedra.

París-Romia, G. (2020). Arte como Simulacro de una Realidad Lejana en la Obra de Gerhard Richter. Barcelona, Research, Art, Creation, 8(2), 101-118. https://doi.org/10.17583/brac.2020.3580

Pavis, P. (1998). Diccionario del teatro. Dramaturgia, estética, semiología. Paídos Comunicación.

Perea, S. (2004). Extranjeras en Roma y en cualquier lugar: mujeres mimas y pantomimas, el teatro en la calle y la fiesta de Flora. Gerión. Revista de Historia Antigua, Anejo VIII: 11-44.

Pessolano, C. (2014). El teatro argentino de postdictadura frente a los postulados de Jerzy Grotowski. Investigación teatral, 4(6): 103-122.

Planella, J. (2006). Corpografías: dar la palabra al cuerpo. Artnodes, revista de intersecciones entre artes, ciencias y tecnología. (6): 1323. http://doi.org/10.7238/a.v0i6.754

Racionero, L. (15 de octubre de 2014). Jane Harrison y el origen sagrado del teatro. La vanguardia, 1-3.

Reznik, C. (2019). El estudio del espectáculo teatral griego antiguo a partir de las fuentes materiales: las pinturas en vasijas de los siglos V y IV a.C. Arqueología, 25(1), 203-220. https://doi.org/10.34096/arqueologia.t25.n1.6013

Rodríguez, F. (1990). Apuntes para una poética del teatro latinoamericano. En Semiótica y teatro latinoamericano. Editorial Galerna-IITCTL.

Rozik, E. (2014). Las raíces del teatro. Repensando el ritual y otras teorías del origen. Colihue. 
Salgado, D. (2007). La dirección de los actores según Stanislavski. Estudios de estudiantes: quaderns de l'Institut del Teatre, (32), 246-269.

San Cristóbal, Ú. P. (2018). ¿Acción, puesta en escena, evento o construcción audiovisual? Una breve introducción al concepto de performance en humanidades y en música. Cuadernos de Música, Artes Visuales y Artes Escénicas, 13(1): 207-231. https://doi.org/10.11144/javeriana.mavae13-1.apee

Sánchez Montes, M. J. (2004). Teoría teatral del siglo XX: El cuerpo y el ritual. Teatro: Revista de Estudios Culturales / A Journal of Cultural Studies, (20): 87-101.

Saura, J. (2015). Los herederos de Stanislavski. Revista Acotaciones. (35): 6184.

Silva, S. (2016). Una mirada al performance de Orlan desde una lectura del CsO. Análisis. Revista Colombiana de Humanidades, 48(88): 213225. https://doi.org/10.15332/s0120-8454.2016.0088.10

Stanislavski, C. (1979). Un actor se prepara. Editorial Diana.

Stanislavski, C. (1980). La construcción del personaje. Alianza Editorial.

Tejo, C. (2019). Discursos desde los Márgenes: Mujer y Arte de Acción en la Galicia Contemporánea. Barcelona, Research, Art, Creation, 7(3) 263-284. https://doi.org/10.17583/brac.2019.3121

Toro-Alé, J. M. (2004). Creativity, body and communication. [Crea-ti-vida-d, cuerpo y comunicación]. Comunicar, 23, 151-159. https://doi.org/10.3916/C23-2004-25

Vélez, M. (2015). Sobre la tragedia griega. Araucaria. Revista Iberoamericana de Filosofía, Política y Humanidades, (33), 31-58.

Teresa Colomina Molina: Profesora Asociada, Doctora en Educación, Departamento de Expresión Plástica, Musical y Dinámica de la Facultad de Educación de la Universidad de Murcia

\section{Email address: colomina@um.es}

Contact Address: : Departamento de Expresión Plástica, Musical y Dinámica de la Facultad de Educación de la Universidad de Murcia. C. Campus Universitario, 12, 30100 Murcia 